\title{
REFLEXÕES SOBRE A EDUCACAOO NO PROJETO DE APROFUNDAMENTO DO NEOLIBERALISMO NO BRASIL
}

\author{
REFLECTIONS ABOUT THE EDUCATION IN THE PROJECT OF DEEPENING \\ NEOLIBERALISM IN BRAZIL
}
REFLEXIONES SOBRE EDUCACIÓN EN EL PROYECTO DE AGRAVAMIENTO DEL NEOLIBERALISMO EN BRASIL

Marcela de Moraes Agudo marcelamagudo@gmail.com

Marília Freitas de Campos Tozoni-Reis mariliaedu@ibb.unesp.br

Lucas André Teixeira lucasandreteixeira@gmail.com

REVISTA PEDAGÓGICA

Revista do Programa de Pós-graduação em Educação da Unochapecó | ISSN 1984-1566

Universidade Comunitária da Região de Chapecó | Chapecó-SC, Brasil Como referenciar este artigo: AGUDO, M. M.; TOZONI-REIS, M. F.; TEIXEIRA, L. A. Reflexões sobre a educação no Projeto de aprofundamento do neoliberalismo no Brasil. Revista Pedagógica, Chapecó, v. 20, n. 45, p. 182-206, set./dez. DOI: http://dx.doi.org/10.22196/rp.v20i45.3997

RESUMO: O artigo aborda a educação no contexto econômico, político e social que atravessamos atualmente no Brasil. A delimitação metodológica para as discussões tomou como unidade de análise a educação na perspectiva histórico-crítica, interpretando como essa conjuntura se relaciona de forma orgânica com a doutrina neoliberal. Estabelecemos como período de análise o início do primeiro mandato da Presidenta Dilma, passando pela chamada Jornadas de Julho de 2013 e culminando no Projeto Ponte para o Futuro, que vem sendo imposto pelo governo Temer configurado a partir do impeachment da Presidenta Dilma Rousseff e se encontra em curso. Realizamos uma análise da conjuntura sem perder de vista os movimentos orgânicos estruturais, cujos resultados indicam os rumos políticos e econômicos que vem sendo imposto por meio de um projeto reformista para a educação brasileira na conjuntura atual: uma proposta que adeque a educação nos marcos do neoliberalismo.

Palavras-chave: Conjuntura. Educação brasileira. Neoliberalismo. Perspectiva histórico-crítica.

\footnotetext{
ABSTRACT

The article approaches the education in economic, political and social context that we cross currently in Brazil. The methodological delimitation for the discussions took as a unit of analysis the education in the historicalcritical perspective, interpreting how this conjuncture is related in an organic way with the neoliberal doctrine. Eestablished as a period of analysis the beginning of the first term of President Dilma, passing through the called Journeys of July 2013 and culminating in the Bridge for the Future Project, which has been promoted by Temer
}

government from the impeachment of President Dilma Rousseff and is currently underway. The analysis of the conjuncture was made without losing sight of the organic structural movements, whose results indicate the political and economic directions that has been imposed through a reformist project for Brazilian education in the current conjuncture: a proposal that adjusts education in frameworks of neoliberalism.

Keywords: Conjuncture. Brazilian education. Neoliberalism. Historic-critical perspective.

RESUMEN: El artículo aborda la educación em el contexto económico, político e social que atravesamos actualmente en Brasil. La delimitación metodológica para las discusiones há tomado como unidad de análisis la educación en la perspectiva histórico-crítica, interpretando cómo esa coyuntura se relaciona de forma orgánica con la doctrina neoliberal. Hemos estabelecido como período de análisis el inicio del primer mandato de la Presidenta Dilma, pasando por la llamada Jornadas de Julio de 2013 y culminando en el Proyecto Puente para el futuro, que se há impuesto por gobierno Temer configurado a partir del impeachment de la Presidenta Dilma Rousseff, y se encuentra en curso. Realizamos un análisis de la coyuntura sin perder la vista de los movimientos orgánicos estructurales, cuyos resultados indican los rumbos políticos y económicos que viene imponiendo por medio de un proyecto reformista para la educación brasileña en la coyuntura actual: una propuesta que adecte la educación en los marcos del neoliberalismo.

Palabras clave: Coyuntura. Educación brasileña. Neoliberalismo. Perspectiva histórico-crítica. 


\section{Introdução}

O atual contexto econômico, político e social que atravessamos atualmente no Brasil tem disseminado em nosso cotidiano crises generalizadas para explicar e justificar uma série de reformas governamentais que, implementadas por um Estado guiado por um projeto neoliberal cada vez mais intenso, advogam a retomada de crescimento econômico, apresentando-as como medidas necessárias para a solução de uma crise financeira que precisa ser combatida e que passará. É importante relembrar que, no segundo mandato do governo Lula, o discurso que se transmitia à população por meio da grande mídia era de que esta crise estrutural do capitalismo não atingiria o Brasil.

Entretanto, para compreendermos esta conjuntura em uma perspectiva de compreensão por meio da raiz contraditória do modo de produção, é preciso entender para além dos discursos oficiais e midiáticos que não possibilitam a compreensão da realidade cotidiana.

Num espaço conjuntural de cerca de 15 anos, o país caminhou da euforia de um crescimento econômico exponencial a uma sucessão de crises. Dadas as profundas transformações advindas da relação espaço-tempo na terceira revolução tecnológica pela qual passamos, Milton Santos (1994) afirma que esses períodos de crises são parte da dinâmica contraditória do capitalismo, que engendrado no desenvolvimento da modernidade foi se disseminando ao longo da contemporaneidade em diversos âmbitos da sociedade: crise de paradigmas; crise ambiental; crise social; crise financeira; crise ética; crise política; crise moral; crise econômica, entre outras crises que, em última análise, denotam uma crise civilizatória que se desdobra em períodos históricos cíclicos e contraditórios e que possui relação intrínseca com o modo de produção capitalista.

Com as orientações teóricas que buscam os pressupostos do materialismo histórico e dialético para compreensão da realidade, o artigo aborda a conjuntura social, econômica e política que se manifesta na conjuntura brasileira e o papel da educação neste contexto. Assim, o problema que se coloca é: ao problematizar a conjuntura da educação brasileira no contexto do neoliberalismo, quais são os elementos que nos permitem compreender o projeto reformista em curso?

A delimitação metodológica para as discussões tomarão como unidade de análise a Educação na perspectiva histórico-crítica (SAVIANI, 2005), tentando estabelecer uma análise de como a essa conjuntura se relaciona de forma orgânica com a doutrina neoliberal, que se despontou no contexto da década de 1960 com a Ditadura Militar, foi incorporada de forma estrutural no contexto de redemocratização do Estado brasileiro, tomando uma abrangência incisiva a partir dos anos de 1990 e culminando com o atual Estado de Exceção que presenciamos hoje. 
Ainda em relação aos parâmetros metodológicos, estabelecemos como período de análise o início do primeiro mandato da Presidenta Dilma, passando pela chamada 'Jornadas de Julho de 2013' e culminando no Projeto 'Ponte para o Futuro', que foi promovido pelo governo Temer, configurado a partir do impeachment da Presidenta Dilma, e se encontra em curso na atualidade. Neste sentido, seguindo as orientações metodológicas propostas por Gramsci (1975, in SAVIANI, 2008, p. 4), buscaremos realizar uma análise da conjuntura sem perder de vista os movimentos orgânicos estruturais.

Para responder ao problema anunciado, abordaremos a conjuntura em que eclodiu as 'jornadas de julho', trazendo elementos que foram se configurando no sentido de diluir a crise do capital em crises generalizadas como parte de um processo de despolitização da compreensão estrutural da crise contraditória, cíclica e orgânica. Esta compreensão recai sobre diversos setores da sociedade, com destaque para o campo da educação.

Num segundo momento, adentramos ao tema da educação, foco central das discussões deste estudo. Neste sentido, a tentativa será a de verificar como esse contexto criou condições para que se aprofundasse uma política reformista da educação brasileira, intensificando o acirramento do neoliberalismo como projeto nas políticas educacionais. Assim, considerando esta conjuntura no processo histórico, o neoliberalismo atualizou, com mãos de ferro, a educação ao contexto de reestruturação econômica, política e social.

\section{Problematizando a conjuntura brasileira: da crise orgânica à despolitização pela via da aparente polarização partidária}

Vivemos em um momento político, econômico e social conturbado, de conflitos e disputas acirrados por uma crise econômica cíclica do sistema político e econômico que se encontra em seu momento neoliberal, a partir da década de 1970, influenciando politicamente as questões sociais de nosso tempo. Esta crise orgânica do capital teve, em 2008, sua mais recentemente e forte erupção, começando nos Estados Unidos e atingindo a Europa, quando os bancos privados contaram com financiamento público, enquanto que o empobrecimento dos trabalhadores foi intensificado (DEL ROIO, 2016).

No Brasil, considerando as decisões tomadas pelos governos anteriores, de aprofundamento do neoliberalismo inseridas no contexto mundial, este cenário de embates tomando as ruas começou a se intensificar em 2013. É importante destacarmos que não estamos reduzindo a luta dos trabalhadores ou a precarização das condições de vida dos trabalhadores, como se esta tivesse iniciado em 2013. As condições cada vez mais precárias de vida dos trabalhadores são combatidas por meio da militância diuturna por 
muitos. Não estamos negando esta história, mas considerando o contexto conjuntural.

Um marco importante naquele momento foram as chamadas 'jornadas de junho', em que parcela significativa da população foi às ruas para demonstrar seu descontentamento. Singer (2013) pondera sobre a referência 'jornadas de junho', que podemos comparar, de maneira irônica ou com franqueza, ao evento debatido por Marx no livro $O 18$ Brumário de Luís Bonaparte, que se refere a um momento conjuntural a partir de 1848, em que os proletários fizeram frente em Paris e foram reprimidos por meio da "ternura da polícia”, evento este em que Marx afirma que a Europa tremeu com o "terremoto de junho". Para refletirmos sobre os sentidos das nossas atuais 'jornadas de junho', de proximidade e de afastamento com a conjuntura francesa do século XIX, é importante entendermos as disputas políticas agora envolvidas.

O aumento da tarifa do ônibus de algumas prefeituras municipais foi o estopim para as manifestações de junho de 2013 no Brasil, em que o Movimento Passe Livre, que agregou manifestantes de esquerda e tem uma ação política organizada desde 2003, teve uma ação intensa na reivindicação de transporte coletivo de qualidade e público, se distanciando da iniciativa privada. Apesar disso, como nos aponta Sanfelice (2014), os manifestantes que compuseram a manifestação tinham reivindicações de natureza distintas, levantando diferentes bandeiras, abarcando, por exemplo, desde bandeiras de partidos políticos, inclusive de esquerda, a reivindicação de uma política partidária, predominantemente.

Neste sentido, considerando que a grande mídia nos países ocidentais exerce grande poder ideológico, que envolve as dimensões econômica, política e social, sua atuação foi fundamental nestas manifestações apartidárias, fazendo com que, em um primeiro momento, a mídia se mostrasse contra as manifestações, mas depois passou a indicar que era um descontentamento, abrindo espaço fecundo para que grupos de direita e conservadores começassem uma atuação mais ampla (SANFELICE, 2014). A fragmentação das jornadas de junho é discutida por Singer (2013), entendendo que houve uma separação, uma divisão do movimento, seguindo distintos caminhos.

Destacamos que muitos partidos políticos levaram suas bandeiras para as manifestações e a maioria dos participantes articulava no sentido de que as manifestações eram apartidárias, mandando que as bandeiras dos partidos fossem retiradas das manifestações. Isso mostra, por um lado, um descontentamento com as organizações dos partidos, que são hierárquicas, burocratizadas e trazem, muitas vezes, uma figura de 'ícone' a ser seguido, mas sem negar os partidos, buscando uma organização mais coletiva e horizontal nestes espaços; por outro lado, demonstra também a negação dos partidos, podendo ser justificada por iniciativas anarquistas. Porém, nesse contexto, 
movimentos de direita, liberais, fortemente conservadores, encontraram um espaço e um público abundante, descontente com as condições da realidade e, portanto, propício para mobilizar-se. Além disso, depois das 'jornadas de junho', com este terreno preparado pelos movimentos de direita e conservadores, com uma ideologia que vai contra as conquistas sociais, inclusive com relação aos direitos humanos, encontraram um espaço confortável para se manifestar, sem qualquer pudor e com muita força e vontade política.

É importante salientar o que Sanfelice (2014) analisa: mobilizações como a do 'passe livre' não se iniciaram em 2013, evidenciando que, apesar de serem muitas as causas envolvidas nas jornadas de junho, nem todas tiveram conotação local e imediata. Apesar disso, Chauí (2013) problematiza a dificuldade de articulação e organização sólida e permanente na maneira como foram constituídas as manifestações. Se por um lado, a convocação via redes sociais mostra uma tentativa de burlar os grandes meios de comunicação, por se convocar por meio de uma chamada de evento pontual nestas redes, é da mesma maneira que se convoca para tantos outros 'eventos', ou seja, não há uma especificidade que caracterize a chamada para a manifestação. Assim, sua organização fica prejudicada e a fragmentação e a pulverização da identidade se mantêm.

Evidenciamos principalmente dois pontos importantes argumentados por Chauí (2013) no que diz respeito às jornadas de junho. $\mathrm{O}$ primeiro diz respeito à convocação via redes sociais, em que, sendo as pessoas apenas usuárias dessas redes e não possuindo o controle político, técnico e econômico, se relacionam com as redes apenas 'apertando um botão'. A lógica é que o que se quer pode acontecer, em um sentido de satisfação imediata, aspectos bastante relacionados à grande mídia na 'sociedade da informação', a qual Duarte (2008) se refere ao analisar as ilusões da chamada 'sociedade do conhecimento'. O segundo ponto diz respeito a aparência de que o movimento foi homogêneo e de massa, reforçado, de acordo com Chauí (2013), pela recusa das mediações institucionais, como os partidos políticos, por exemplo.

A partir das jornadas de junho, podemos entender que seria um aspecto fundamental a organização e a incorporação de grupos sociais progressistas e revolucionários, que historicamente buscam a transformação da sociedade, para que as manifestações seguissem ganhando um corpo revolucionário (SANFELICE, 2014). Contudo, nas últimas décadas, com o aprofundamento da política econômica neoliberal, os partidos e sindicatos foram se enfraquecendo. Espaços importantes para fortalecimento do movimento trabalhista foram cada vez mais cooptados e os movimentos mais radicais dos trabalhadores foram se fragmentando.

Assim, o caráter 'sem partido' se firmou no movimento evidenciando que os partidos políticos governantes são 
1 Na perspectiva marxista que assumimos para esta análise, a agenda materialista diz respeito a produção e reprodução da vida sem a exploração do trabalho. Nesta condição, temos a superação do trabalho alienado. Considerando a conjuntura, precisamos compreender concretamente os grupos que fazem parte e que estão juntos dos trabalhadores, considerando a realidade concreta de vida dos trabalhadores e a necessidade material de superação das condições de exploração a que estão submetidos. responsáveis pela condição precária de vida da população, pois utilizam dos meios públicos para atender a interesses privados, provocando condições precárias de vida para a maior parte da população. No entanto, este fato também demonstra a falta de conhecimento de que vivemos um sistema político-partidário fruto da ditadura, indicando como saída a negação dos partidos em qualquer forma e organização (CHAUÍ, 2013). Contudo, podemos entender que a ênfase dada às manifestações ditas 'apartidárias' pela grande mídia, na realidade, evidencia as disputas de poder que se tornam cada vez mais acirradas.

Não podemos deixar de ressaltar o papel da grande mídia para que a classe média, sob a ideologia conservadora, se incorporasse ao movimento. O poder ideológico da grande mídia, respaldado pela burguesia financeira, permitiu que as manifestações fossem se transmutando para uma mobilização 'patriótica' contra a corrupção, se manifestando num primeiro momento de maneira genérica, para depois assumir manifestações contra a corrupção dos partidos no poder. Neste sentido, apesar de emergir de uma massa de pessoas despolitizadas, foi se acirrando a polarização política no Brasil. Ou seja, as intenções e a ideologia da grande mídia se moveram para trazer os grupos representantes da direita no poder, trabalhando para que vençam a disputa de poder que está colocada.

Ainda em relação às jornadas de junho, é importante ponderarmos que os grupos sociais nas extremidades são mais facilmente identificados, reforçando um estado de polarização política. A direita levantando uma bandeira patriota, moralista e anticorrupção e a esquerda denunciando as condições de pauperização da maioria da população, com questões sociais ligadas aos direitos humanos. Contudo, não podemos fazer vista grossa a um grupo que contribuiu para dar corpo às mobilizações, que foi o chamado de centro. Esse grupo tem a capacidade de pegar as bandeiras da esquerda e da direita e retirar das reivindicações a necessidade do confronto (SINGER, 2013). Assim, de acordo com Singer (2013), o centro evidencia uma nova agenda, no contexto de um "pós-materialismo", em que o aprofundamento das precárias condições de vida das populações, os interesses privados dos grupos no poder e a crença pessoal, munida de opiniões sem fundamentos, encerradas em si mesmas e colocadas acima de fatos objetivos, possibilitou a constituição desse movimento com diferentes vertentes. Singer (2013) aponta que, para os proletários, a agenda que prevalece, como necessária, é a materialista ${ }^{1}$. Neste sentido, é importante que as perspectivas mais progressistas se articulem na busca pela concretização de tal agenda.

Para entendermos um pouco mais deste contexto, é interessante compreendermos o caráter da democracia estabelecida nos países no ocidente. Losurdo (2004) explica a relação entre a democracia e o mercado, problematizando a questão do sufrágio. O mercado político atua em que, para seu funcionamento, os consumidores-eleitores têm 
difícil acesso para verificar o produto comprado/votado, o que é, em partes, justificado pela publicidade política, em que a grande mídia é a responsável pelo "esclarecimento político" (LOSURDO, 2004). Como sabemos, este esclarecimento é carregado e velado pela ideologia hegemônica, configurando um esclarecimento totalmente enviesado pelos interesses da burguesia financeira, bastante distantes dos interesses dos trabalhadores.

Assim, esse autor discute que o regime que triunfou no século XX se constitui um bonapartismo soft, em que há um líder fortalecido pela investidura popular, exercendo amplos poderes, inclusive na condição de estado de exceção, restringindo os direitos dos subalternos, ou seja, um governo autoritário e violento no exercício de poder. Deste modo, a democracia vai se tornando uma palavra vazia, na medida em que o povo, destituído de autonomia produtiva política e à mercê da grande mídia, designa o presidente da nação.

Na América Latina, a burguesia que controla a sociedade e os grupos externos que se aproveitam desta condição promovem a manutenção da condição de capitalismo dependente, sob a hegemonia dos Estados Unidos, numa relação colonial ou neocolonial. Essa relação foi muito bem analisada por Fernandes $(1975$, p. 52), que já afirmava que nunca houve a "descolonização" desses países, pois "o complexo colonial sempre foi necessário à modernização e sempre alimentou formas de acumulação de capital que seriam impraticáveis de outras maneiras". Assim,

É o modo de privilegiamento interno das classes "altas" e "médias", cujos setores dominantes e elites dirigentes forjam o seu espírito capitalista especial, alicerçado na combinação da dependência com o subdesenvolvimento, que determina a "lógica do capitalismo dependente" e o caráter ultra-egoístico, autocrático e conservador de suas estruturas de poder elitista (FERNANDES, 1975, p. 100, destaques do autor).

A articulação política da dependência se constitui em muleta fundamental para garantir a replicação econômica interna e externa. Neste contexto, a partir do início dos anos 2000, com os candidatos do Partido dos Trabalhadores (PT), Lula e Dilma, chegando à presidência, uma frente política foi formada, dirigida pela burguesia do país. Essa frente envolveu a classe trabalhadora excluída do poder, no sentido de que a burguesia obteve vantagens na medida em que governos próximos às camadas populares mobilizaram uma aproximação destas classes, de acordo com Boito Jr (2012).

Lembremos que ao final da década de 1990, uma parcela da grande burguesia interna acumulou contradições no programa neoliberal implantado naquele momento, ao mesmo tempo em que o movimento sindical popular so- 
freu dificuldades cada vez maiores. Essa situação proporcionou condições para a organização de uma frente ampla liderada pelo PT, com um programa que buscou o crescimento econômico do Brasil sem romper com o neoliberalismo, mas mantendo a proximidade com as camadas populares pela implantação de programas que trouxeram "alguma transferência de renda” (BOITO JR, 2012). É importante ressaltarmos também que a aceleração do crescimento da economia na última década, que resultou da elevação das commodities brasileiras, permitiu aos governos aumentar os gastos sociais e a proteção trabalhista (ANTUNES; BRAGA, 2014).

Com isso, acreditou-se que o caminho para a superação dos problemas sociais no Brasil seria a relação e aproximação de parcela da burguesia com a maioria da classe trabalhadora (TONET, 2013). O modelo de governo neoliberal que se autoproclamou popular buscou uma conciliação de classes, com medidas econômicas, políticas e sociais muito mais populistas do que populares.

Se por um lado, algumas medidas de aumento - muito mais do que transferência - de renda para os pobres foram tomadas, por outro o agronegócio, a mineração e outros produtos primários foram fortemente apoiados por medidas como a priorização do financiamento para as principais empresas vinculadas a esses setores e o fortalecimento regional do Mercosul, em detrimento de outros blocos econômicos, o que foi fortalecendo a burguesia interna. Então, podemos afirmar que para o PT a classe trabalhadora não ocupou mais o papel de força dirigente do partido, mas de base social de apoio (BOITO JR, 2012). Ainda assim, como identificaram Antunes e Braga (2014) as lideranças do PT foram incorporadas ou 'cooptadas', por meio de cargos administrativos de assessoramento e controle sindical dos fundos de pensão, conduzindo o movimento sindical a uma ‘fusão' com o aparelho de Estado. Essa estratégia levou a um descontentamento dos trabalhadores com as organizações sindicais, permitindo a desarticulação e fragmentação da esquerda.

Fernandes (1975, p. 101) já apontava que estratégias reformistas sempre podem ser usadas para enfrentar as condições desfavoráveis de sociedades organizadas sob o modo capitalista dependente, analisando duas vias para isso. É interessante perceber como estas duas vias se constituíram em tentativas utilizadas nos governos do PT: "fortalecer, segundo ritmos bastante rápidos, a incorporação dos países latino-americanos no espaço econômico, sociocultural e político das nações hegemônicas", justificando assim o status quo; e outra via que se constitui na "multiplicação rápida dos pontos de disseminação dos "privilégios estratégicos", de modo a universalizá-los no seio das classes "médias" e a torná-los mais frequentes nos "setores explosivos" das classes "baixas", que acaba por atender a massa popular com a ilusão da ascensão social e os setores conservadores por defender uma "institucionalização da revolução". 
É importante percebermos, neste contexto, que apesar de interesses distintos dos diferentes grupos sociais, esses estiveram juntos para a manutenção dos mandatos de Lula na presidência e no primeiro mandato de Dilma. Mesmo com intenções e justificativas distintas, com o agravamento da crise econômica mundial e a crise política no Brasil, o apoio destas diferentes classes ao governo se manteve e, por isso, constituem um mesmo campo político (BOITO JR, 2012).

Nesse sentido, caminhando pela via do governo de coalizão, as alianças políticas dos governos Lula e Dilma se confirmaram. Isso fortaleceu uma confusão ideológica e política na população em geral, além do agravamento de condições como a violência e o aumento do desemprego, por exemplo (TONET, 2013). Mas, é claro que não foi essa "confusão" a causa da crise política no Brasil.

Um aspecto importante que Tonet (2013) levanta é que a polarização não deveria ser compreendida como entre esquerda vinculada ao PT e direita vinculada ao Partido da Social Democracia Brasileira (PSDB), mas entre capital e trabalho, a questão fundamental da sociedade. Neste sentido, Antunes e Braga (2014, p. 43) afirmam:

Afinal, além dos avanços da formalização, do mercado de trabalho aquecido e dos ganhos reais do salário mínimo, o atual modelo de desenvolvimento também se apoiou sobre o aumento do número de acidentes de trabalho, o incremento do ritmo da rotatividade do trabalho, a elevação das taxas de terceirização e flexibilização da força de trabalho, além do declínio do atendimento do transporte público, da saúde e da educação, que estão na linha de frente das atuais manifestações.

Ou seja, continuamos aqui com os avanços e retrocessos em permanente tensão. A equiparação dos direitos trabalhistas das empregadas domésticas foi um outro aspecto importante do governo Dilma em relação aos avanços no mundo do trabalho. Assim, a alta burguesia, incomodada com essas medidas dos governos do PT, que não passaram de medidas que tiveram importância, mas compensatórias, se movimenta em apoio ao seu pseudo inverso, o PSDB. Em 2011, Dilma chega ao poder, e as medidas para enfrentar o aprofundamento da crise foram tomadas, como os cortes do orçamento público e a tentativa de reestruturação política, mas todas elas tomadas a partir de iniciativas neoliberais. Como explica Boito Jr (2012), no contexto neodesenvolvimentista há diversas contradições que possibilitam a desagregação política, ou seja, há diversas contradições que possibilitam que grupos de esquerda ou de direita retirem seu apoio ao governo.

Examinando a situação, vemos que a possibilidade de uma das partes abandonarem a frente neodesenvolvimentista é real. O PSDB 
procura atrair a grande burguesia interna sugerindo - há coisas que não se deve dizer abertamente... - que fará uma redução drástica nos gastos sociais do Estado e que cortará as asas do movimento camponês; as organizações de extrema esquerda procuram fazer com que os sindicatos e o campesinato retirem o apoio que dispensam ao Governo Lula (BOITO JR, 2012, p. 104).

É importante percebermos que esse 'neodesenvolvimentismo' não foi desenvolvido no capitalismo brasileiro nos governos do PT, como explica Del Roio (2016) ao discutir que não houve desenvolvimento das forças produtivas na ciência e na tecnologia. Assim, mesmo com a agroindústria e o capital financeiro caminhando bem, as forças produtivas na ciência e na tecnologia não se desenvolveram.

No entanto, os temas mais presentes e mais duradouros nas manifestações que culminaram nos protestos de 2013 foram sociais e políticos e se intensificaram no segundo mandato do governo de Dilma, a partir de 2014. Nelas veio à tona a insatisfação de diferentes grupos com os pactos e apoios realizados para que o PT chegasse ao governo no Brasil. Se esses pactos, durante os dois mandatos do presidente Lula e no primeiro da presidenta Dilma, embora presentes, não se expressavam tão claramente nas manifestações, no segundo mandato de Dilma Rousseff eles estiveram muito mais claros, já indicando a ruptura que estava por vir. É importante destacar a crise política que foi gerada pelas delações de corrupção que atinge vários parlamentares e até o Presidente em exercício Michel Temer.

Assim, as manifestações de 2013 foram bastante contraditórias, da mesma maneira que os grupos são constituídos por diferentes classes e suas frações, suas intenções e interesses também não se constituem as mesmas. Com o agravamento da crise econômica mundial não tardou a aparecer, no contexto interno, seus reflexos. Os setores que tinham alguns interesses atendidos deixaram de tê-los. Alguns grupos se movimentaram no sentido de buscar conservar suas condições, e outros aproveitaram para reivindicar.

Neste sentido, podemos perceber a hegemonia da pequena política. Coutinho (2010), baseado em Gramsci, explica que consiste no consenso passivo de diferentes grupos sociais, em que os valores das classes dominantes são compreendidos como naturais inclusive pela classe subalterna e, desta maneira, compreende-se a política não como instrumento de luta entre diferentes projetos de sociedade, mas como um instrumento administrativo, à parte da vida do homem médio. A pequena política é mais estampada no contexto neoliberal que a grande política, envolvendo o infoidividualismo, o privatismo e a naturalização das relações sociais como valores da concepção de mundo hegemônica.

Em meio a esse contexto, a hegemonia da pequena política na conjuntura no Brasil atual se reduz a um bipartidarismo entre PT e PSDB que, praticando a mesma polí- 
tica econômica e social, as reduzem a uma questão técnica, administrativa, nutrindo a servidão financeira. Como resultado desse processo, "a elite política brasileira, escudada pela grande mídia, pelos bancos e pelas classes médias rentistas" (SANTOS, 2016, p. 13), empreendeu um processo de despolitização da compreensão estrutural da crise, deflagrando um contexto de crises generalizadas por meio de uma aparente polarização partidária em detrimento de uma compreensão orgânica da crise.

Com isso, passamos a tratar da educação neste contexto, entendendo as condições geradas para que se empreendesse uma política reformista da educação brasileira, intensificando o neoliberalismo como projeto nas políticas educacionais.

\section{O reformismo na educação brasileira: a ponte para o futuro é o acirramento do neoliberalismo}

A partir das transformações históricas do processo de modernização das sociedades, a educação tem um papel estratégico, no neoliberalismo não é diferente. Silva (2007) nos lembra que a luta entre projetos de sociedade não é intelectual entre atores bem-intencionados para decidirem o melhor sistema de educação para a sociedade, mas uma luta de recursos materiais e de instrumentos culturais e simbólicos, que são intencionais e fazem parte de uma concepção de mundo, auxiliando na formação e legitimação desta concepção de mundo. Deste modo, esse aspecto "educativo" também se apresenta e faz parte das propostas educacionais e de outros âmbitos e políticas sociais (SILVA, 2007).

Por isso, além de denunciarmos o projeto neoliberal, é necessário também desvelarmos o processo em que o projeto neoliberal se dedica a determinar nossa função social, por meio do desenvolvimento de nossa concepção de mundo. A educação no projeto neoliberal propõe que aspectos políticos e sociais sejam encarados como questões técnicas, com a qualidade total e o construtivismo contribuindo para que identidades individuais sejam produzidas de modo a atender a ideologia econômica neoliberal (SILVA, 2007).

A educação escolar passou a ser ofertada à toda a população, incorporando todos os grupos sociais a um ensino que historicamente era exclusividade de uma parcela pequena da população. Isso trouxe muitas mudanças na oferta da educação escolar no Brasil. Temos hoje uma política educacional pautada na eficácia do processo, buscando o maior resultado com menor custo, indo pelo caminho de que o desemprego é um problema dos indivíduos que não souberam escolher a educação correta ou do poder público que não a ofereceu, no sentido de que é necessário um "ajuste" entre o sistema escolar e a empresa (ENGUITA, 2007).

A qualidade total e sua gestão - a educação neoliberal - trata a educação como um serviço ou um bem que o 
mercado oferece para satisfazer as mesmas necessidades materiais ou equivalentes. Na educação, portanto, "a palavra de ordem da qualidade encerra também um segundo significado: não o melhor (em vez do mesmo ou de menos) para todos mas para uns poucos e igual ou pior para os demais" (ENGUITA, 2007, p. 107).

Sabemos que a modernidade trouxe para a educação nas escolas uma organização do trabalho educativo adequada ao esquema de organização industrial, hoje atualizada ao modelo empresarial. Sob a lógica neoliberal, a qualidade do ensino passa a ser uma estratégia competitiva no mercado. A escola sob o modelo da qualidade total entende os conflitos como barreiras para o desenvolvimento, considerando os rankings como fundamentais para verificar a qualidade. Agências internacionais têm forte influência e reforçam medidas governamentais de privatização escolar e universitária. O discurso da democratização - como acesso de todos ao ensino - foi paulatinamente substituído pelo de qualidade, constituindo a "nova retórica conservadora no campo educacional", sendo que, para transformar esta condição, precisamos enfrentar a contradição entre acesso à escola e o serviço proporcionado por ela (GENTILI, 2007). O que significa qualidade na educação do ponto de vista dos diferentes e contraditórios grupos sociais das sociedades organizadas sob o modo capitalista de produção?

Neste sentido, assistimos o investimento na educação das massas, uma educação altamente ideológica, presente em programas como "empresas cidadãs", "trabalho voluntário", ou seja, setores produtivos dominantes atuando politicamente nas "questões sociais". A partir de 2006, o foco passou a ser a educação pública, se configurando uma estratégia política muito bem articulada, contando com apoio direto de muitos organismos e pessoas, proporcionando a necessidade de harmonia social, "colaboração" social (MARTINS, 2009).

O Banco Mundial teve uma mudança em sua atuação e diversas outras organizações foram criadas em seu interior. Estas organizações apoiam os processos de privatização, por meio de assessorias e apoio e proteção financeiros, bem como patrocínio de estudos acerca de oportunidades de educação privada e mercado de financiamento estudantil, gerando lucro a partir dos investimentos em educação (KRUPPA, 2001).

Com isso, Martins (2009) conclui que o empresariado busca a manutenção da dependência da ordem internacional, por meio de parcerias e co-participação em prol das empresas, desenvolvendo uma educação nesse sentido:

[...] da construção de novas subjetividades identificadas com o capital, no plano valorativo, e da elevação mínima do patamar de racionalidade da força de trabalho, no plano técnico-científico, viabilizando, mais facilmente, a difusão dos parâmetros da nova sociabilidade e a legitimação dos empresários 
como classe dirigente e dominante (MARTINS, 2009, p. 26).

Esta condição atende ao projeto neodesenvolvimentista, em que um acordo nacional foi articulado, sendo dirigido pelos empresários, atuando direta e indiretamente em diversos setores da sociedade, configurando em uma nova ofensiva burguesa na educação no país. Este bloco no poder, no sentido do conceito fundamentado em Poulantzas (1980), vem liderando as ações inclusive educativas no país, e o Estado agindo como organizador das diferentes frações de classe que compõem o bloco. Essa retroalimentação de interesses entre o público e o privado tem pautado as agendas reformistas atuais na educação.

Em 2014, as manifestações contra a Copa do Mundo com suas obras milionárias e a corrupção envolvida provocaram a eleição do segundo mandato da presidenta Dilma como mais um governo do PT, mas agora com margem estreita. Pudemos verificar também a eleição de políticos reacionários que passaram a compor um Congresso Nacional também muito mais conservador: a 'bancada do boi, da bíblia e da bala', como ficou conhecida a presença de políticos diretamente ligados a igrejas evangélicas, agronegócio e indústria de armas (DEL ROIO, 2016).

Enquanto eclodiam as manifestações contra o governo federal e a atenção da grande mídia e consequentemente da população estava voltada para isso, no Estado de São Paulo, há mais de vinte anos governado pelo PSDB, medidas contra a educação foram tomadas. A principal ação reformista foi o anúncio da chamada 'reorganização escolar', em que as etapas da Educação Básica atendidas pelas escolas públicas do Estado de São Paulo seriam reorganizadas. Por exemplo, uma escola que atendia os anos finais do Ensino Fundamental e o Ensino Médio, passaria a atender apenas uma dessas etapas. A escolha da etapa que permaneceria na unidade escolar seria apenas anunciada para alunos, responsáveis e professores. Ou seja, não seria uma medida debatida na comunidade escolar e tampouco decidida por ela.

Os estudantes, acostumados a cursar o Ensino Fundamental em uma escola que já constitui parte de sua identidade, onde têm seus amigos e, muitas vezes, está localizada perto de sua casa, sem participar desse processo, tiveram suas vidas alteradas. Da mesma maneira, o professor, que pode conseguir ter a maior parte da carga horária de trabalho em uma determinada escola, teria agora que ser removido para outras escolas, podendo ter suas aulas distribuídas em três ou até mesmo quatro escolas diferentes. Ou seja, a medida reformista de contexto neoliberal propôs uma reorganização escolar que significa mais um passo na precarização da educação escolar pública do Estado de São Paulo.

O argumento do governo do Estado de São Paulo para realizar a reorganização foi de que os ciclos únicos nas 
2 De acordo com notícia da mídia, um ano após o "escândalo da merenda", o processo não foi finalizado e tem arrastado uma decisão. Disponível em <http://www1. folha.uol.com.br/poder/2017/02/1857971-escandalo-da-merenda-faz-1-ano-sem-punicao.shtml?cmpid=facefolha $>$ Acesso em 12 fev 2017. escolas facilitariam a gestão e melhor rendimento dos estudantes, com base nas avaliações externas, além de que a Educação Básica estaria em processo de diminuição de sua demanda (CÁSSIO et al., 2016).

Contudo, a partir de dados quantitativos e qualitativos, Cássio et al. (2016) revelam que não há evidências científicas que sustentem a relação da reorganização com o melhor desempenho dos estudantes. Esses autores apresentaram também alguns dados que trazem novas análises acerca da demanda da Educação Básica, para além da população matriculada e da população na faixa dos 6 aos 17 anos, pois fatores outros econômicos, sociais e culturais podem dificultar ou impedir o acesso à escola. Por exemplo, de acordo com eles, 37.640 crianças e adolescentes de 6 a 14 anos e 245.467 jovens entre 15 e 17 anos estavam fora da escola no Estado de São Paulo e, dentre os que as frequentavam, uma grande parte não estava na idade-série ideal. Além disso, o processo de diminuição da demanda, uma das justificativas oficiais da reorganização, também é um argumento frágil na medida que o número de crianças e adolescentes tende a se estabilizar, em São Paulo, em torno de 3,5 milhões de matrículas.

O desgaste do governo do Estado de São Paulo na gestão Alckmin por conta de um grave processo de acusações sobre corrupção, com destaque para o uso do dinheiro destinado à merenda ${ }^{2}$ dos estudantes das escolas da rede pública estadual, somado à manifestação dos estudantes contra a reorganização por meio da ocupação das escolas, fez com que, na tentativa de minimizar sua impopularidade, o governo adiasse a reorganização escolar, causando, inclusive, a queda do Secretário da Educação, Herman Voorwald. Se a reorganização planejada tivesse se concretizado, 94 escolas teriam sido fechadas (1,6\% do total), 754 teriam os ciclos atendidos reestruturados (13,3\% do total), afetando cerca de 311 mil estudantes e suas famílias e 71 mil docentes (CÁSSIO et al., 2016).

No entanto, essa política reformista de reorganização vem sendo realizada desde 2016, ainda que de maneira velada, no Estado de São Paulo, por meio de medidas. De acordo com Cássio et al. (2016), uma resolução autorizou que as turmas excedessem em 10\% o número de alunos permitido e indicado pelos referenciais internacionais de qualidade. Com isso, a redução de funcionários, o fechamento de salas, ciclos e modalidades vem ocorrendo desde então.

Entretanto, essa política não se limita ao Estado de São Paulo, mas se manifesta na educação de vários estados brasileiros. No Estado de Goiás, de acordo com Catini e Mello (2016, p. 1180), "no início de 2016 já existiam 27 escolas geridas pela Polícia Militar (PM), e outras 15 estavam em processo de "militarização"”, sem contar com a transferência da gestão das escolas estaduais para Organizações Sociais, por meio de decreto em 2015, expedido pelo governador deste Estado, do PSDB, Marconi Perillo (CATINI; MELLO, 2016). 
Assim, percebemos a tendência em curso no país de uma política reformista e privatizadora da educação pública, que faz parte do projeto neoliberal. Desde o começo do século, viemos acompanhando programas governamentais para a inclusão social ao sistema educacional, evitando o aprofundamento da desigualdade social, o que poderia resultar em conflitos mais intensos. Com isso, a composição do Estado nesta organização cumpre este papel. Isso significa que a população tem acesso a um nível mínimo de bem-estar, para se sentir socialmente incluída. A desigualdade de oportunidades acompanha os jovens quando tentam ingressar no mercado de trabalho, dificultado pelo alto grau de desemprego. Neste sentido, podemos considerar que a educação escolar no Brasil hoje tende muito mais em adequar os alunos à lógica de mercado do que proporcionar uma educação de qualidade socialmente referenciada (POCHMANN; FERREIRA, 2016).

Também não podemos deixar de considerar que, no bojo dessas políticas reformistas educacionais, a ideologia do movimento por uma 'escola sem partido' ganhou força, encontrando respaldo no poder político de deputados conservadores. Este movimento começou em 2004, com a iniciativa do advogado Miguel Nagib, advogado e procurador do Estado de São Paulo e fundador do 'movimento escola sem partido'; e apoio dos deputados Flávio e Carlos Bolsonaro, ambos do Partido Social Cristão (PSC). Com o fortalecimento das posições políticas conservadoras, vários projetos de lei municipais, estaduais e federais, com o objetivo de implantar a 'escola sem partido', estão em tramitação no Brasil.

A 'escola sem partido' constitui-se, desde então, em um movimento que busca combater uma suposta onda de doutrinação ideológica de esquerda que estaria presente nas escolas públicas por meio de controle e vigilância do trabalho docente. É inacreditável, mas esse movimento tenta impedir que os direitos humanos de combate à homofobia e ao machismo, por exemplo, sejam tratados nas escolas, assim como a defesa da liberdade de expressão e da laicidade na escola pública. Isso demonstra o cunho profundamente reacionário e conservador da proposta da 'escola sem partido', expressando, portanto, que de 'sem partido’ não há nada: é a defesa acirrada dos valores conservadores. Assim, podemos identificar um profundo caráter ideológico querendo ser implementado de maneira controladora e autoritária sobre o trabalho do professor, ferindo qualquer indício de autonomia que ainda poderia restar no trabalho docente. Vale mencionar que os professores que lecionam nas escolas públicas são os professores nas condições mais precarizadas de trabalho.

O Movimento da Escola sem Partido toma por principal inimigo o professor. Ataca diretamente esse profissional na sua liberdade acadêmica. A construção do trabalho docente 
seria determinada pelos interesses privados das famílias e comunidades e, em detrimento dos conteúdos públicos estabelecidos em diretrizes ou das escolhas pedagógicas das escolas e seus docentes. Acrescente-se a isso o controle ideológico, forma de censura que não viabiliza o direito a uma educação republicana, não privada e que, necessariamente, passa pela garantia de liberdade, de diversidade e pluralismo nas escolas (SANFELICE, 2016, p. 131).

Sob o referencial da Pedagogia Histórico-Crítica (SAVIANI, 2005) e do materialismo histórico-crítico, além da realidade em que vivemos, é fundamental argumentarmos contra um projeto como o da 'escola sem partido', que apenas contribui para revelar o fortalecimento dos setores conservadores na crise estrutural do capitalismo. Aqui temos, de forma inquestionável, a realidade econômica, política e social explicitando a estreita relação entre educação e política, um aspecto vastamente estudado por diversos pesquisadores em educação no Brasil. Compreendemos que justamente por esse potencial político e de mudança que a educação carrega é que os setores conservadores e reacionários, nesse momento explicitado pelo movimento da escola sem partido (ou da mordaça), tem tanto interesse em controlar as escolas públicas.

É importante registrar que várias associações se manifestaram contra o projeto da 'escola sem partido'. A presidente da ANPED, por exemplo, enviou carta aos deputados federais dizendo 'não' ao projeto 'escola sem partido'. O Sindicato Nacional dos Docentes das Instituições de Ensino Superior (ANDES-SN) também vem se manifestando constantemente contra o projeto. Foi formada uma Frente Nacional pela Educação, composta por entidades como partidos, sindicatos, movimento estudantil, além de deputados e vereadores repudiando o Projeto de Lei 867/2015, da 'escola sem partido', fortalecendo o movimento por uma escola sem mordaça. É necessário entendermos que a 'escola sem partido' atende aos setores conservadores da burguesia brasileira, pois busca controlar o processo de ensino e de aprendizagem nas escolas públicas, fazendo com que a ideologia conservadora se mantenha e que nenhuma perspectiva progressista, e muito menos revolucionária, contra a condição precária desta realidade, seja alimentada.

Passadas as eleições de 2014, o segundo governo Dilma, já em 2015, começou a perder o apoio dos setores da burguesia garantido até então aos governos do PT. Os diferentes setores foram buscando seus interesses e se distanciando do governo. O Poder Judiciário contribuiu com o desgaste do governo iniciando uma operação contra a corrupção onde vários membros do PT estavam envolvidos, dissipando a coalizão estabelecida até então. Na tentativa de se manter no poder, o governo Dilma apostou em mais concessões e acordos entre os partidos em busca da manu- 
tenção da base de sustentação no Congresso Nacional. Com o apoio do parlamento e do poder judiciário fragmentados, estas iniciativas não foram suficientes para impedir a movimentação colocada. Em abril de 2016 tivemos o início do processo que culminou com o impeachment da Presidenta Dilma Rousseff (DEL ROIO, 2016) em 31 de agosto de 2016. As manifestações pós-impeachment dos diferentes partidos mais a esquerda no parlamento brasileiro mostra uma divisão acerca da análise de que o impeachment tenha se configurado ou não como um golpe parlamentar.

Com isso, o afastamento de Dilma e "a montagem do novo governo expressou a real correlação de forças no parlamento, um parlamento eleito sem dúvida por quem tinha mais dinheiro, mas expressão também da sociedade civil, mesmo que com distorções" (DEL ROIO, 2016, p. 14). Assim, de acordo com Del Roio (2016), identificamos aqui uma crise na composição do Estado.

Neste sentido, Michel Temer, do Partido do Movimento Democrático Brasileiro (PMDB), vice-presidente, depois do período interino, com a aprovação do processo de impeachment (ou golpe parlamentar) da Presidenta Dilma, passou a governar como Presidente em exercício. Neste contexto, seu grupo lançou o projeto reformista, intitulado: "Ponte para o Futuro".

Com o impeachment concretizado e Temer passando de presidente interino, condição em que ficou de março a agosto de 2016, para presidente em exercício, o projeto reformista de cunho conservador se intensificou, no escopo do projeto neoliberal, passam a ter urgência no contexto deste governo com apoio do parlamento. Programas sociais são diminuídos drasticamente e o esforço para que o Estado seja cada vez mais privatizado, atendendo aos interesses da hegemonia burguesa, é intensificado. No entanto, a crise política continua e podemos percebê-la de forma mais evidente nas negociações das substituições dos ocupantes dos cargos no primeiro escalão do governo, exigidas principalmente pelas acusações de corrupção que os atinge.

Podemos perceber que, as manifestações lideradas pelos movimentos liberais, em processo de fortalecimento desde 2013, questionavam "quem iria pagar o pato", se referindo à corrupção, conquistando, deste modo, setores da classe média. Lembremos que muito antes dos governos do PT e inclusive nele, os trabalhadores da cidade e do campo vem "pagando o pato" do aprofundamento de suas condições de precarização. Neste sentido, entendemos que o caminho essencial para a sociedade brasileira nesse momento é a já conhecida "revolução contra a ordem" por meio da explosão popular e do socialismo" (FERNANDES, 1975, p. 102). Ou seja, compreendemos que, cada vez mais e mais, é fundamental que sejamos claros e enfáticos na luta pela sociedade socialista, inclusive nesse momento em 
que a violência das decisões políticas e econômicas contra os pauperizados vem se intensificando cada vez mais.

Podemos perceber que o governo Temer vem sendo composto majoritariamente pela burguesia conservadora e empresarial. O programa reformista do governo se pauta pelo aprofundamento do neoliberalismo, por meio do mecanismo das privatizações vem atacando os direitos trabalhistas e sociais, caminhando para um bonapartismo nada soft. Com isso, preservam-se as relações sociais estabelecidas. Percebemos, desta maneira, que não há uma política "conciliadora" como no governo do PT pretendeu. Se, principalmente no governo Lula, os movimentos sociais permaneceram fragmentados e com pouca força de mobilização e reivindicação, no contexto do governo Temer, a tendência é de os movimentos sociais serem convocados e fortalecerem mobilizações contra o governo. O governo Temer já está dando muitos motivos para este fortalecimento.

Ainda como parte desse projeto reformista, a Proposta de Emenda Constitucional (PEC) 241/2016, transformada em Emenda 55 para tramitar no senado, foi "como tirar da veia o pouco sangue que ali sobrava", como discute Sanfelice (2016) ao indicar que as garantias constitucionais que temos já são insuficientes e bastante distantes das necessidades reais e que, com a aprovação do congelamento dos gastos do Estado durante 20 anos, o que propõe a referida PEC, verificamos que o campo da privatização será ampliado, principalmente no que se refere à educação e à saúde

Essa PEC, agora aprovada, promove uma drástica diminuição nos investimentos públicos em programas sociais. Como explica Antunes (2006), o trabalho na contemporaneidade está sustentado sob um tripé: a terceirização, a flexibilização e a precarização, constituindo o projeto reformista de acirramento neoliberal. O trabalho terceirizado, diminuindo custos para as empresas, se constitui numa condição para o caminho contrário ao que a Consolidação das Leis do Trabalho (CLT) conduz. Somando-se a isso, a tecnologia vai acabando com postos de trabalho, exigindo que o trabalhador desenvolva várias outras funções e ocupações. Isso aprofunda a precariedade das condições de trabalho, inclusive com o adoecimento do trabalhador. Com isso, se não há resistência dos sindicatos para utilizar táticas de defesa do trabalhador, a CLT, de fato, se extinguirá.

A reforma da previdência em tramitação no Congresso também é mais uma medida extrema do governo Temer rumo ao aprofundamento neoliberal do afastamento do Estado com relação aos direitos sociais. Com base nas discussões de Antunes (2006), podemos compreender que, com a reforma da previdência, a precarização dos professores se aprofundará em duas dimensões: a da condição de professor, em que o tempo de serviço para a aposentadoria será o mesmo de outros trabalhadores; e a condição de gênero, considerando-se que a maioria dos professores é mulher e por isso tem uma jornada muito maior de 
3 Entrevista disponível em <https://youtu. be/aaGgrHkeDYw>. Acesso em 15 fev 2017.
4 Reportagem acerca da medida tomada em uma prefeitura de convocar professores voluntários para lecionarem nas escolas. Disponível em: <http://g1.globo.com/ sp/piracicaba-regiao/noticia/2017/02/ prefeitura-apela-voluntarios-paraconseguir-iniciar-ano-letivo-em-sp.html>. Acesso em 14 fev 2017. trabalho ao considerarmos o trabalho doméstico, pois terá o mesmo tempo de serviço que os outros trabalhadores para a aposentadoria pela proposta de reforma.

Uma outra intenção do governo com a reforma da previdência é incentivar o mercado para as iniciativas de previdência privada, onde a classe média já vem buscando possibilidades de melhores condições de aposentadoria. Como nos indica Ricardo Antunes, em entrevista cedida à Frente Sindical Classista ${ }^{3}$, em Santos em fevereiro de 2017, a previdência pública vem sendo demolida e a previdência privada não garante a aposentadoria, pois pode quebrar. $\mathrm{O}$ modelo chileno, implementado nos anos 1980 pelo ditador Pinochet, é um exemplo de um modelo fracassado de aposentadoria para o trabalhador.

Assim, atendendo os interesses do sistema financeiro e da burguesia industrial, o projeto reformista do governo Temer está em curso. No orçamento do Estado brasileiro, muito mais dinheiro vai para pagar os juros da dívida pública do que o que é o gasto com os programas sociais. Apesar disso, como nos indica Ricardo Antunes, os juros e a dívida pública são remuneração do capital financeiro, o que explica porque os juros são tão altos no Brasil.

A nova organização do trabalho neste contexto reformista envolve até mesmo trabalho voluntário ${ }^{4}$. Em fevereiro de 2017, em uma cidade do interior do Estado de São Paulo, de acordo com a prefeitura, houve um atraso no processo seletivo para contratação de professores e, então, para não atrasar em cerca de quinze dias o início do ano letivo, foi solicitado para que moradores, professores e estudantes dos cursos de licenciatura assumissem turmas, de maneira voluntária, enquanto os professores não fossem contratados. É importante dizer que as pessoas se voluntariaram, afirmando que estavam "fazendo sua parte" para que as crianças não ficassem sem aulas.

Esse debate contextualizado da educação é importante para percebermos as relações de poder que estão estabelecidas na realidade e que perpassam e constituem as várias dimensões que compõem a educação no Brasil contemporâneo. Outra reforma que foi implementada pelo governo Temer é a Medida Provisória (MP) 746, que foi promulgada na forma da Lei 13.145/2017. Trata-se da mais profunda reforma da Lei 9394/1996, Lei de Diretrizes e Bases da Educação Brasileira (LDB) em vigor.

A reforma do Ensino Médio é uma das reformas do chamado pacote de reformas que o governo Temer vem agilizando com a aprovação do Congresso, passando por cima da opinião pública e dos movimentos sociais. A reforma do Ensino Médio diz respeito a 60\% do currículo dos três anos da etapa serem preenchidos pela Base Nacional Curricular Comum (BNCC) e, então, manter apenas matemática, português e inglês como disciplinas obrigatórias no Ensino Médio, e os outros 40\% serão constituídos pelos itinerários formativos, ou seja, pelas outras disciplinas, que serão optativas. Os estudantes escolherão os blocos de disciplinas ao indicar as áreas em que irão se aprofundar. As áreas propostas são: linguagens e suas tecnologias, matemática e suas tecnologias, ciências da natureza e suas 
tecnologias, ciências humanas e sociais aplicadas, formação técnica e profissional.

Esta reforma está sendo implementada sem qualquer diálogo, de maneira unilateral. A ANPED, a maior entidade científica da Educação no Brasil, criticou, afirmando que a reforma é autoritária em sua forma e equivocada em seu conteúdo. As principais críticas e manifestações foram no sentido de retirarem as disciplinas de arte, educação física, sociologia e filosofia do currículo. Por conta da pressão social, estas disciplinas foram mantidas na BNCC, que norteará a educação formal no Brasil.

Muito mais do que oferecer opções conforme o "talento" dos estudantes, argumentação oficial proclamada, o que podemos verificar nessa proposta é que a flexibilização atingiu a Educação Básica:

[...] Sob a aparência de escolha e participação, a GQT [Gestão da Qualidade Total] impõe uma visão de educação e gerência educacional que fecha a possibilidade de se pensar de outra forma. A verdadeira escolha consistiria em poder rejeitar a própria idéia de qualidade total, o que equivaleria a rejeitar toda a noção neoliberal de educação (SILVA, 2007, p. 21).

Em relação aos professores, a reforma aprovada também autoriza a contratação de profissionais com "notório saber" para atuar na educação técnica e profissional. Essa proposta fundamenta-se, obviamente, numa concepção de competência do professor que se esgota no domínio do conteúdo, aspecto imprescindível, mas insuficiente para a atuação docente, considerando a fundamental importância da formação pedagógica. Um aspecto importante que os formadores de professores precisam se mobilizar diz respeito a alteração que a MP do Ensino Médio institui na LDB e que mudará a formação de professores no Brasil. O Artigo sétimo da MP aprovada dia 15 de fevereiro pelo Senado altera o artigo 62 da LDB, por meio da inserção do parágrafo 8 que diz: "Os currículos dos cursos de formação de docentes terão por referência a Base Nacional Comum Curricular". Ou seja, a autonomia que resta às unidades universitárias para elaboração de seu currículo para a formação dos professores será ainda mais reduzida, inclusive, possivelmente, com diminuição da carga horária dos professores. Esta condição convoca a articulação e mobilização política dos professores e dos formadores de professores para o enfrentamento da precarização de seu trabalho e de sua formação.

\section{Conclusão}

Com o objetivo de responder ao problema anunciado para a produção do conhecimento deste estudo, consideramos que os rumos políticos e econômicos que o 
5 Vídeo disponível em <https://www.youtube.com/watch?v=7_FdhibioyQ $>$. Acesso em 12 fev 2017. governo atual vem impondo se inserem claramente num projeto específico para a educação brasileira na conjuntura atual: uma proposta que adeque a educação nos marcos do neoliberalismo. Tal proposta encontra desenvolvimento material pela via do reformismo, sendo este um meio para organização da nova configuração do trabalho, que, para a vida do trabalhador professor significa o aprofundamento da precarização; já, para os sujeitos da classe subalterna, significa uma educação com claras intenções de adequação à reestruturação produtiva do capital, com finalidade última de manter e aumentar os níveis de acumulação daqueles que possuem os meios de produção na periferia do sistema.

Um exemplo claro disso pode ser verificado por meio da propaganda oficial da reforma do Ensino Médio ${ }^{5}$ Na propaganda, "estudantes" do Ensino Médio se levantam indicando qual profissão desejam seguir. Um fala que quer fazer curso técnico, outro que quer ser designer de games, outro jornalista e uma garota, que quer ser professora, é a única, dentre os que se apresentam, que afirma que ser professor 'é o que ama'. Por um lado, a propaganda indica a adequação do novo Ensino Médio à flexibilização das demandas de mercado, por outro, a propaganda explicita a ideologia dominante em nossa sociedade da desvalorização da profissão docente, naturalizando uma atividade que, ao invés de ser encarada como profissão, pode ser exercida 'por amor'.

Apesar do discurso sobre a profissionalização docente estar atrelado à perspectiva gerencialista, podemos notar que a ideologia de ensinar por 'dom' e o ensino 'por amor' vem sendo veiculada pelo governo em diferentes instâncias, o que prejudica ainda mais a valorização docente e o trabalhador professor. Este quadro não nos é estranho: configura a condição de trabalho flexível, explicitando o projeto neoliberal que vem sendo implementado no Estado de São Paulo e em outros estados desde o chamado período de democratização.

Essa configuração, alinhada ao projeto reformista que abordamos ao longo desse estudo, demonstra um claro retrocesso histórico em relação à trajetória científica da educação e da pedagogia como ciência da e para a educação (SAVIANI, 2005). Embora reconheçamos essa dimensão concreta na conjuntura atual, consideramos que a resposta ao problema anunciado precisa ir além dessa perspectiva, visto que tentamos evidenciar ao longo do estudo o projeto que está em curso em relação à educação brasileira, no sentido de intensificação e aprofundamento do neoliberalismo na periferia do capital.

Assim, as lutas sociais precisam buscar convergência para o enfrentamento do agressivo projeto neoliberal em curso no contexto do capitalismo internacional com fortes reflexos no Brasil hoje. Um caminho fundamental é a resistência política. Em 2016, no Paraná, o movimento estudantil se organizou e iniciou a ocupação das escolas públicas do 
6 Reportagem disponível em: <http://www1.folha.uol.com.br/ educacao/2016/11/1828305-ocupacao-de-escolas-murcha-no-pr-em-meio-a-protestos-e-acoes-judiciais.shtml>. Acesso em 25 jan 2017.
Estado, com um pico de 850 escolas ocupadas de um total de 2.100 escolas públicas paranaenses ${ }^{6}$. As ocupações tiveram a intenção de protestar pela democratização da mídia e contra a reforma do Ensino Médio. As ocupações pressionaram também o governador do Paraná, Beto Richa, do PSDB, que não quis dialogar com o conjunto dos estudantes nas escolas ocupadas. Esse movimento foi se ampliando para todo o país. Assim, universidades também agregaram ao movimento, totalizando cerca de 1000 escolas e instituições de ensino superior ocupadas em todo o país.

Um aspecto importante destas ocupações em 2016 diz respeito à aplicação do Exame Nacional do Ensino Médio (ENEM), prova que permite que candidatos ingressem ao Ensino Superior, além da certificação de conclusão do Ensino Médio. Em muitas escolas ocupadas, o exame seria aplicado e, mesmo ameaçados, os estudantes do Estado do Paraná não desocuparam as escolas e, nestas escolas, a prova foi remarcada. Neste período, no Estado de São Paulo, houve diversas tentativas de ocupação, mas a polícia militar do Estado de São Paulo cumpriu as ordens de desocupar as escolas sem mandado, no ano de 2016.

Apesar disso, no quarto trimestre de 2015 os estudantes secundaristas paulistas reagiram às medidas reformistas impostas para a reorganização do ensino e iniciaram o movimento de ocupação das escolas. O movimento teve início da cidade de São Paulo, com a ocupação da Escola Estadual Diadema e, no dia seguinte, a Fernão Dias. Este movimento se ampliou, atingindo escolas de todo o Estado, inclusive do interior, chegando a cerca de 205 escolas ocupadas.

Não podemos deixar de destacar a greve dos professores da rede estadual de São Paulo em 2015, que durou mais de três meses, a mais longa da história, sem que o governo estadual cedesse, se recusando a negociar e cortando o ponto dos grevistas. Foi uma greve simbólica, porém os professores não conseguiram qualquer tipo de avanço nas condições de trabalho por parte do governo. No Paraná, o massacre do dia 29 de abril de 2015 contra os professores, pelo governo Richa, em Curitiba, ficou conhecido como o Massacre do Centro Cívico, em que 200 professores foram feridos durante protesto contra o Projeto de Lei 252/2015, proposto por Richa, que modificava a Previdência Social de professores, e que estava em votação pelos deputados estaduais naquele dia.

Isso demonstra a valorização das escolas e dos profissionais professores pelos estudantes e pela própria categoria que lá trabalham, ao mesmo tempo que também evidencia a necessidade e o anseio por uma outra organização escolar, por uma instituição social que cumpra com a função social de formação humana, com condições plenas para que professores e estudantes possam desenvolver esse processo de formação humana. Com isso, concluímos com a perspectiva de que a resistência coletiva por meio de mobilizações e movimentos sociais populares seja o 
meio basilar para enfrentamento de reformas governamentais que aprofundam as condições de precarização dos explorados.

\section{Referências}

ANTUNES, Ricardo. Os sentidos do trabalho: ensaio sobre a afirmação e a negação do trabalho. 8 reimpress. São Paulo: Boitempo, 2006.

ANTUNES, Ricardo; BRAGA, Ruy. Os dias que abalaram o Brasil: as rebeliões de junho, julho de 2013. R. Pol. Públ. São Luís, Número Especial, p. 41-47, 2014.

BOITO JR, Armando. Governos Lula: a nova burguesia nacional no poder. In: BOITO JR., Armando; GALVÃO, Andreia. (Orgs.). Política e Classes sociais no Brasil dos anos 2000. São Paulo: Alameda, 2012, 430 p.

CÁSSIO, Fernando Luiz; CROCHIK, Leonardo; DI PIERRO, Maria Clara; STOCO, Sérgio. Demanda social, planejamento e direito à educação básica: uma análise da rede estadual de ensino paulista na transição 2015-2016. Educ. Soc., Campinas, v. 37, n. 137, 2016.

CATINI, Carolina de Roig; MELLO, Gustavo Moura de Cavalcanti. Escolas de luta, educação política. Educ. Soc., Campinas, v. 37, n. 137, 2016.

CHAUÍ, Marilena. O inferno urbano e a política do favor, tutela e cooptação. Revista Teoria e Debate, v. 113, p. 1-5, 27, jun. 2013.

COUTINHO, Carlos Nelson. A hegemonia da pequena política. In: RIZEK, Cibele Saliba; OLIVEIRA, Francisco; BRAGA, Ruy. Hegemonia às avessas: economia, política e cultura na era da servidão financeira. São Paulo: Boitempo, 2010.

DEL ROIO, Marcos Tadeu. As Muitas Faces da Crise Brasileira. Práxis e Hegemonia Popular. Rio de Janeiro, ano 1, n. 1, dez, 2016.

DUARTE, Newton. Sociedade do conhecimento ou sociedade das ilusões? Quatro ensaios crítico-dialéticos em filosofia da educação. 1 ed., 1 reimpress. Campinas, SP: Autores Associados, 2008.

ENGUITA, Mariano Fernandez. O discurso da qualidade e a qualidade do discurso. In: GENTILI, Pablo Antonio Amadeo; SILVA, Tomaz Tadeu da (Orgs.). Neoliberalismo, qualidade total e educação. 12 ed. Petrópolis, RJ: Vozes, 2007. 
FERNANDES, Florestan. Capitalismo dependente e classes sociais na América Latina. 2 ed. Rio de Janeiro: Zahar, 1975.

GENTILI, Pablo Antonio Amadeo. O discurso da "qualidade" como nova retórica conservadora no campo educacional. In: GENTILI, Pablo Antonio Amadeo; SILVA, Tomaz Tadeu da (Orgs.). Neoliberalismo, qualidade total e educação. 12 ed. Petrópolis, RJ: Vozes, 2007.

KRUPPA, Sonia Maria Portella. O Banco Mundial e as políticas públicas de educação nos anos 90. Anais da 24 ${ }^{\mathbf{a}}$ Reunião anual da ANPED, Caxambu. 24a, 2001.

LOSURDO, Domenico. Democracia ou bonapartismo: triunfo e decadência do sufrágio universal. Rio de Janeiro: Editora UFRJ/Editora UNESP, 2004.

MARTINS, André Silva. A educação básica no século XXI: o projeto do organismo "Todos pela Educação". Práxis Educativa, Ponta Grossa, v.4, n.1, 2009.

POCHMANN, Márcio; FERREIRA, Eliza Bartolozzi. Escolarização de jovens e igualdade no exercício do direito à educação no Brasil: embates do início do século XXI. Educ. Soc., Campinas, v. 37, n. 137, 2016.

POULANTZAS, Nicos. O Estado, o poder, o socialismo. Rio de Janeiro: Edições Graal, 1980.

SANFELICE, José Luís. Vandalismo ou movimento social? As jornadas de junho (2013). Germinal: Marxismo e Educação em Debate, v. 6, p. 4-14, 2014.

SANFELICE, José Luís. A conjuntura educacional atual: para onde caminha a educação. In: SANFELICE, José Luís; SIQUELLI, Sônia Aparecida (Orgs.). Desafios à democratização da educação no Brasil contemporâneo. Uberlândia: Navegando Publicações, 2016.

SANTOS, Fábio Luis Barbosa dos. Além do PT: a crise da esquerda brasileira em perspectiva latino americana. São Paulo: Elefante, 2016.

SANTOS, Milton. Técnica. Espaço. Tempo. Globalização e meio técnico-científico informacional. São Paulo: HUCITEC, 1994.

SAVIANI, Dermeval. Pedagogia histórico-crítica: primeiras aproximações. 9 ed. Campinas: Autores Associados, 2005

SAVIANI, Dermeval. História das idéias pedagógicas no Brasil. Campinas: Autores Associados, 2008. 
SILVA, Tomaz Tadeu da. A "nova" direita e as transformações na pedagogia da política e na política da pedagogia. In: GENTILI, Pablo Antonio Amadeo; SILVA, Tomaz Tadeu da (Orgs.). Neoliberalismo, qualidade total e educação. 12 ed. Petrópolis, RJ: Vozes, 2007.

SINGER, André. Brasil, junho de 2013: classes e ideologias cruzadas. Novos estud. - CEBRAP, n. 97, São Paulo, 2013.

TONET, Ivo. Sobre as atuais manifestações. Revista

Espaço Acadêmico. Especial protestos no Brasil, 2013.

Recebido em: 29/09/2017

Aprovado em: 18/10/2018

Publicado em: 31/12/2018 